\title{
EDUCAÇÃO EM SAÚDE NO PROGRAMA DE APOIO AO PACIENTE DIABÉTICO: UM RELATO DE EXPERIÊNCIA
}

\begin{abstract}
Mônica Martins Binatti
Profissional de Educaçâo Física, Universidade do Extremo Sul Catarinense, monicabinatti@hotmail.com

Micheli Boaroli

Psicóloga, Universidade do Extremo Sul Catarinense, micheliboaroli@hotmail.com

Luize Romancine

Enfermeira, Universidade do Extremo Sul Catarinense, luize-romancine@hotmail.com

Ioná Bez Birollo

Coordenadora da Residência Multiprofissional, Universidade do Extremo

Sul Catarinense, ionavieira71@hotmail.com Joni Márcio de Farias Doutor, Universidade do Extremo Sul Catarinense, jmf@unesc.net
\end{abstract}

\section{RESUMO}

Atualmente, estima-se que a população mundial com diabetes é de 382 milhôes de pessoas, devendo atingir 471 milhôes em 2035, de acordo com a Sociedade Brasileira de Diabetes - SBD (2015). Dados brasileiros de 2011 
mostram que as taxas de mortalidade por Diabetes Mellitus (DM) (por 100 mil habitantes) são de 30,1 para a população geral (SBD, 2015). Desenvolver açóes de educação em saúde para pacientes com diabetes cumpre importante papel para diminuir as incidências de complicaçôes, enfatizando a importância do autocuidado, orientando as pessoas com diabetes a melhorarem seu controle glicêmico e a reduzirem os problemas relacionados à doença (PORTERO; CATTALINI, 2005). O Ministério da Saúde define educação em saúde como o conjunto de práticas do setor que contribui para aumentar a autonomia das pessoas no seu cuidado e no processo educativo de construçáo de conhecimentos em saúde, que visa à apropriação da temática pela população (BRASIL, 2006). Neste contexto, o objetivo deste estudo foi orientar os pacientes do Programa de Automonitoramento Glicêmico Capilar (PAMGC), da Universidade do Extremo Sul Catarinense (UNESC), sobre a importância do estilo de vida saudável no tratamento da diabetes. As reunióes do grupo de apoio aos pacientes diabéticos eram organizadas pelos residentes do Programa de Residência Multiprofissional e, inicialmente, os encontros ocorriam todas as segundas-feiras à tarde, nas Clínicas Integradas da UNESC, em forma de roda de conversa. Após a conclusão das atividades planejadas do primeiro semestre de 2015, o grupo de residentes se reuniu e criou um novo formato de intervenção para otimizar a interação do grupo. No segundo semestre de 2015, os encontros passaram a acontecer duas vezes por mês, e não somente em forma de roda de conversa, mas acrescentando o conteúdo mais prático em cada tema abordado. $\mathrm{O}$ encontro do presente relato foi organizado pelas profissionais de enfermagem, psicologia e profissional de educação física, sendo o primeiro a ser organizado no novo formato, tendo como foco lembrar o que foi apresentado anteriormente, explicar a nova proposta de intervenção e conduzir os participantes a uma prática de atividade física. Ao iniciar o encontro, a psicóloga lembrou os temas que foram apresentados no primeiro semestre de atividades: instruçóes sobre aplicação da insulina e armazenamento da medicação, complicaçóes crônicas do diabetes, alimentação saudável, autoestima e depressão, orientaçóes e benefícios do exercício físico e cuidados com a saúde bucal. Posteriormente, solicitou-se aos participantes que falassem o que mais lhes chamou atenção, porque e o que eles gostariam que fosse apresen- 
tado nos próximos encontros do novo semestre. Após as anotaçôes, explicou-se de que forma os encontros iriam acontecer nas próximas semanas. Entregou-se um calendário, além de fazer um convite ao grupo para a primeira atividade prática, que foi uma aula de dança com diversos estilos musicais. Nos intervalos da prática, a enfermeira orientou sobre o que é e como avaliar a frequência cardíaca. A profissional de educação física explicou como utilizar a frequência para controlar a intensidade do exercício, além dos cuidados que o paciente diabético deve ter ao iniciar um programa de exercício e os benefícios da atividade física para a saúde. Destacou-se que a ação em educação e saúde, no Programa de Apoio ao Diabético, ampliou a experiência multiprofissional e facilitou o acesso dos participantes ao conhecimento teórico-prático, a fim de estimular a autonomia e o autocuidado do paciente no tratamento da doença e suas implicaçóes, sendo esta uma característica marcante da educação em saúde. A iniciativa de tornar o encontro mais dinâmico também aproximou os pacientes da realidade, que antes era apenas percebida por figuras ou pela exposição verbal dos profissionais. Observou-se que, após a mudança na abordagem dos temas, a frequência nos encontros aumentou e o interesse da atividade prática foi da maioria dos participantes, não tendo o envolvimento apenas daqueles que tinham algum comprometimento.

Palavras-chave: Diabetes; Educação em saúde; Estilo de vida.

\section{REFERÊNCIAS}

BRASIL. Secretaria de Gestão do Trabalho e da Educação na Saúde. Câmara de regulaçáo do trabalho em saúde. Brasília: Ministério da Saúde; 2006.

PORTERO, K. C. C.; CATTALINI, M. Mudança no estilo de vida para prevenção e tratamento do Diabetes Mellitus tipo 2. Saúde em Revista [on-line], v.7, n.16, p.63-9, 2005.

SBD. Diretrizes da SBD, 2014-2015. São Paulo: AC Farmacêutica, 2015. 